\title{
Application of Thermochemical Modeling to Assessment/Evaluation of Nuclear Fuel Behavior
}

\author{
Theodore M. Besmann \\ Nuclear Engineering Program \\ University of South Carolina \\ Jacob W. McMurray and Srdjan Simunovic \\ Oak Ridge National Laboratory
}

\begin{abstract}
The combination of new fuel compositions and higher burn-ups envisioned for the future means that representing fuel properties will be much more important, and yet more complex. Behavior within the oxide fuel rods will be difficult to model owing to the high temperatures, and the large number of elements generated and their significant concentrations that are a result of fuels taken to high burn-up. This unprecedented complexity offers an enormous challenge to the thermochemical understanding of these systems and opportunities to advance solid solution models to describe these materials. This paper attempts to model and simulate that behavior using an oxide fuels thermochemical description to compute the equilibrium phase state and oxygen potential of LWR fuel under irradiation.
\end{abstract}




\section{Introduction}

Understanding and predicting nuclear fuel behavior in power reactors has been a longstanding problem due to the complexity of phenomena and the difficulty representing them separately and in concert. For light water reactors (LWRs), which are either pressurized water (PWRs) or boiling water reactors (BWRs) and even heavy water reactors such as the CANDU systems, the fuel consists of $\sim 95 \%$ dense uranium dioxide pellets $\sim 1 \mathrm{~cm}$ in diameter and height, encased in a zirconium alloy cladding which then makes up a fuel rod (Table 1). Mixed oxide (MOX) fuel, i.e., fuel that consists of uranium with several percent plutonium, is also used in in some LWRs and behaves similarly. MOX used in fast neutron spectrum reactors face exacerbated fuel behavior issues due to fast neutron damage, higher average temperatures, and potentially higher burnups.

\section{Table 1}

Dimensions of fuel rods for PWR and BWR systems.

\begin{tabular}{|l|l|}
\hline Pressurized Water Reactor & Boiling Water Reactor \\
\hline Pellet diameter $8.19 \mathrm{~mm}$ & Fuel Pellet OD: $9.55 \mathrm{~mm}$ \\
\hline Outside diameter $9.50 \mathrm{~mm}$ & Fuel Rod OD: $11.18 \mathrm{~mm}$ \\
\hline Cladding thickness $0.57 \mathrm{~mm}$ & Clad Thickness: $0.71 \mathrm{~mm}$ \\
\hline Total Rod Height: $3660 \mathrm{~mm}$ & Total Rod Height: $4179 \mathrm{~mm}$ \\
\hline
\end{tabular}

In recent years efforts to improve the oxide microstructure (form larger grains to retain noble fission product gases) or creep behavior has resulted in doping $\mathrm{UO}_{2}$, for example, with $\mathrm{Al}_{2} \mathrm{O}_{3}$, $\mathrm{Cr}_{2} \mathrm{O}_{3}$, and $\mathrm{Nb}_{2} \mathrm{O}_{3}$ [1-3]. In addition, dopant levels of $\mathrm{Gd}_{2} \mathrm{O}_{3}$ are often included as burnable poisons for nuclear reactivity control early in the life of the fuel rod. While these have become common for specific fuel manufacturers or nuclear units, they will not be considered in the current analysis.

It has long been realized that the behavior of nuclear fuel depends in part on the phases present, their amounts, and their composition. In particular, oxygen potential and oxygen-to-uranium $(\mathrm{O} / \mathrm{U})$ ratio. The $\mathrm{UO}_{2}$ fuel phase by itself exhibits a complicated relationship between composition (O/U ratio) and properties, exemplified by its wide homogeneity range, where it can be extensively either hypo- or hyperstoichiometric at even modestly elevated temperatures [4]. Mihaila et al. [5] and Ramirez et al. [6], for example have modeled the significant dependence of oxygen transport and thermal conductivity on the $\mathrm{O} / \mathrm{U}$ ratio, and demonstrated its effect on inreactor fuel temperature and subsequent thermal expansion/displacement. The chemical behavior also affects the adjoining cladding alloy in terms of oxidation and stress corrosion cracking caused by oxygen and corrosive fission product release from the fuel [7-9].

The ability to predict the chemical state and elemental potentials in nuclear fuel undergoing irradiation is now seen as important to accurate fuel performance modeling, whether under normal or abnormal operations. It has prompted efforts to now include thermochemical models to predict local chemical and phase states in fuel performance codes. For example, Piro et al. [10], have recently demonstrated coupling a thermochemical solver with isotopic evolution and heat transport. Efforts are underway to couple thermochemical analysis to a number of fuel performance codes. 
There is substantial complexity in understanding fuel chemical behavior under irradiation that has so far prevented accurate representation. There have been, however, a number of significant efforts to understand the chemical state of fuel under irradiation ranging from direct assessment of individual elements and their likely association [11-13], experimental efforts with simulated fuels [14-19], and first principles approaches [20-22]. Thermodynamic values for fuel and fission product phases, while to various degrees still limited, have been used in several efforts to begin to treat fuel with a global thermochemical model. Imoto [17] and Cordfunke and Konings [13] examined the separate behaviors of the various fuel constituents. Corcoran et al., [23] also performed experiments with simulated fuel compositions coupled with modeling for a limited set of the important fission products. Besides Piro et al., [10] and Corcoran et al., [23] Moriyama and Furuya [24] and Loukusa et al. [25], also made some of the first efforts to apply a thermochemical free energy minimization of fuel compositions to obtain expected phase assemblages and critical values such as oxygen potential. Piro et al., [10] in particular investigated reproducing the radial oxygen potential profile across an LWR fuel pellet utilizing the computed radial burnup behavior and resulting elemental distribution. The current effort has adopted more physically representative models for the fuel and included more components within the models than have largely been previously applied. These have been used together with an evaluation of likely clad oxidation to attempt to reproduce observed burnup behavior.

\section{Phases considered in burnup analysis}

Depletion calculations were performed using ORIGEN-S [26, 27] to generate transmutation and fission product compositions in typical LWR fuel with a starting $\mathrm{O} / \mathrm{U}$ ratio of 2 . The results are seen graphically in Fig. 1 for elements present in higher than trace amounts, with burnup to 102.5 GWd/t for a PWR 14x14 array fuel assembly. An example list of the elements and their concentration from significant burnup $(62.5 \mathrm{GWd} / \mathrm{t})$ is seen in Table 2. Also indicated is whether the element will likely dissolve in the fluorite structure $\mathrm{UO}_{2}$ or form a secondary phase in fuel, and what type of phase following that of the review of Lewis et al. [28] and the earlier assessments noted above.

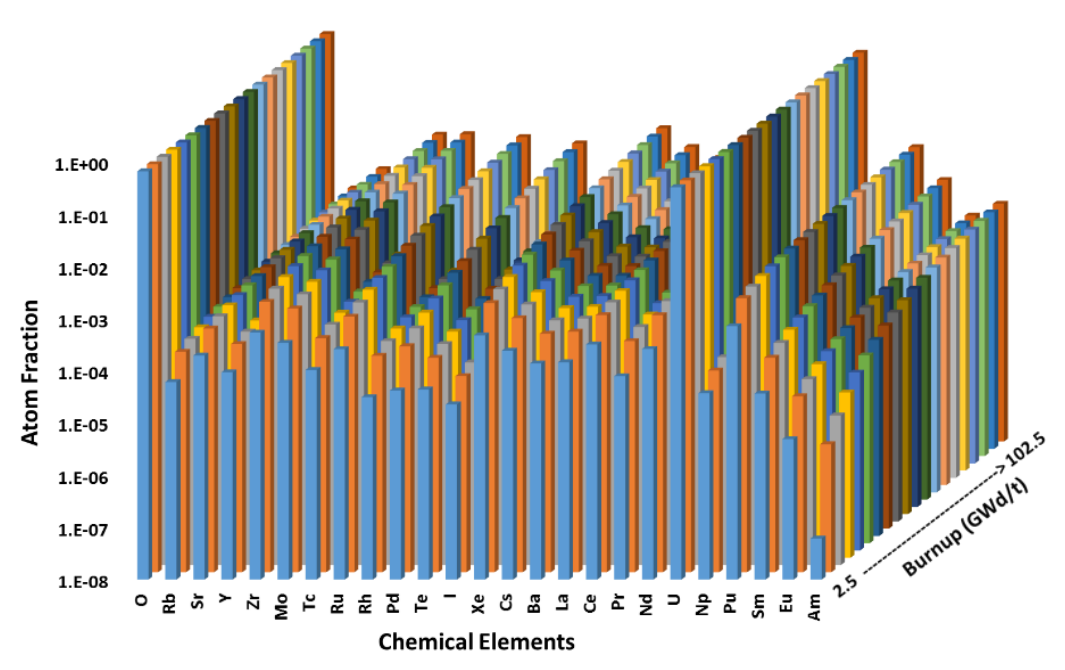


Fig. 1. Computed elemental fission product and transuranic atomic fractions from 2.5 to 102.5 $\mathrm{GWd} / \mathrm{t}$.

\section{Table 2}

Concentration of greater than trace fission product and transmutation elements generated in typical PWR fuel having undergone burnup to $62.5 \mathrm{GWd} / \mathrm{t}$ and their likely chemical form after Lewis et al. [24].

\begin{tabular}{|c|c|c|c|}
\hline Element & Millimole/original mol U & Secondary phase tendency & $\underline{\text { Secondary Phase Form }}$ \\
\hline $\mathrm{Xe}$ & 19.25 & Strong & Elemental gas \\
\hline $\mathrm{Zr}$ & 16.09 & Somewhat & Oxide \\
\hline Mo & 15.23 & Strong & Metallic and oxide \\
\hline $\mathrm{Ru}$ & 12.33 & Strong & Metallic \\
\hline $\mathrm{Pu}$ & 11.88 & None & \\
\hline $\mathrm{Nd}$ & 11.67 & None & \\
\hline Cs & 9.05 & Strong & Oxide \\
\hline $\mathrm{Ce}$ & 8.63 & None & \\
\hline $\mathrm{Pd}$ & 7.66 & Strong & Metallic \\
\hline $\mathrm{Ba}$ & 4.90 & Strong & Oxide \\
\hline $\mathrm{Sr}$ & 3.93 & Strong & Oxide \\
\hline $\mathrm{La}$ & 3.92 & None & \\
\hline $\operatorname{Pr}$ & 3.42 & None & \\
\hline Tc & 3.28 & Strong & Metallic \\
\hline $\mathrm{Sm}$ & 2.07 & None & \\
\hline $\mathrm{Y}$ & 2.05 & None & \\
\hline $\mathrm{Te}$ & 1.77 & Strong & Metallic \\
\hline $\mathrm{Kr}$ & 1.72 & Strong & Elemental gas \\
\hline $\mathrm{Rb}$ & 1.61 & Strong & Oxide \\
\hline $\mathrm{Rh}$ & 1.54 & Strong & Metallic \\
\hline $\mathrm{Np}$ & 0.88 & None & Metallic \\
\hline I & 0.80 & Strong & Elemental or iodide \\
\hline $\mathrm{Gd}$ & 0.68 & None & \\
\hline $\mathrm{Cd}$ & 0.67 & Strong & Metal \\
\hline Am & 0.55 & None & \\
\hline $\mathrm{Eu}$ & 0.49 & None & \\
\hline $\mathrm{Cm}$ & 0.40 & None & \\
\hline $\mathrm{He}$ & 0.38 & Strong & Elemental gas \\
\hline $\mathrm{Ag}$ & 0.37 & Strong & Metal \\
\hline $\mathrm{Pm}$ & 0.35 & None & \\
\hline $\mathrm{Se}$ & 0.29 & Strong & Metallic \\
\hline $\mathrm{Sn}$ & 0.27 & Strong & Metallic \\
\hline $\mathrm{Nb}$ & 0.12 & Somewhat & Oxide \\
\hline $\mathrm{Br}$ & 0.11 & Strong & Elemental or bromide \\
\hline
\end{tabular}


The composition and chemical activities of potential phases that will form during burnup can be computed from free energy minimization for the system, which are chemical equilibrium calculations. These in turn require models for variable stoichiometry phases such as the $\mathrm{UO}_{2 \pm \mathrm{x}}$ phase with dissolved fission products and transuranics. The resulting database for use in global equilibrium calculations for fuel undergoing burnup can be generated from the phase models and thermochemical values.

\subsection{Fluorite structure fuel phase}

The fluorite structure constituent remains the major phase in LWR fuel even at high burnup as only a small fraction of uranium is consumed [14, 23, 24, 28, 29]. The phase can accommodate substantial dissolution of +3 and +4 valence atoms, and there is an exceptionally wide composition range for the lanthanide and transuranic elements which are largely, if not exclusively, present in the phase. Zirconium, an abundant fission product is also expected to partition to a significant extent to the fluorite phase.

In the adopted approach the fluorite phase is represented by a compound energy formalism (CEF) model for $\mathrm{UO}_{2 \pm x}$ developed by Gueneau et al. [4] after Hillert [30, 31]. It is a three sublattice model with cations mixing on the first sublattice and oxygen and vacancies occupying the second (tetragonal) and third (octahedral) sublattice. Vacancies in the oxygen sublattices and the presence of a second oxygen-vacancy sublattice allow for a variable oxygen-to-metal (O/M) ratio allowing both hypo-and hyperstoichiometry. No cation vacancies or interstitials are included under the assumption that their formation are energetically unlikely.

Available system assessments for transuranic and fission product elements with U-O were used to generate the multicomponent fluorite phase thermodynamic model.

$(\mathrm{U}, \mathrm{Pu}, \mathrm{Y}, \mathrm{Nd}, \mathrm{La}, \mathrm{Pr}, \mathrm{Gd}, \mathrm{Ce}, \mathrm{Zr})_{1}(\mathrm{O}, \mathrm{Va})_{2}(\mathrm{O}, \mathrm{Va})_{1}$

Note that only ternary systems of U-O with a single additional cation were integrated into the phase thermodynamic model with no higher order interactions considered. This is adequate as the bred transuranics and fission products are present in low concentrations and thus the probability of interactions among them is negligible.

The U-Pu-O system model was adopted from Gueneau et al. [4]. Ternary models of U-O with individual lanthanides were taken from a series of studies by McMurray et al. [32-34], Brese et al. [35], and Lee et al. [36]. The CEF relations for the U-O fluorite phase containing $\mathrm{Zr}$ were adopted from the Thermodynamics of Advanced Fuels-International Database [37]. Lanthanides not yet incorporated in the fluorite phase model ( $\mathrm{Sm}, \mathrm{Eu}, \mathrm{Pm})$ were considered independently, i.e., as separate oxide phases, as was the case for the transuranic elements Am and Cm. While this is less accurate than their inclusion as solutes in the fluorite structure phase, the interim approach will allow for near accurate determination of phase states and oxygen potential.

\subsection{Metallic phases}


The most abundant secondary phases observed in fuel are the noble metal or "white phases." They are inclusions in fuel and are readily seen in micrographs of irradiated fuel samples [3840]. Kaye et al. [41] have performed an assessment for the 5 noble metal alloy (Mo-Pd-Rh- $\mathrm{Ru}-$ Tc) that can form in fuel under irradiation and developed useful regular solution models for the potential fcc, hcp, and bcc phases.

\subsection{Secondary oxide phases}

A variety of secondary actinide-fission product oxide phases ("grey phases") are possible based on the thermochemistry of the fuel. Considered in the current calculations are $(\mathrm{Sr}, \mathrm{Ba}) \mathrm{UO}_{4},(\mathrm{Rb}$, $\mathrm{Cs})_{2} \mathrm{UO}_{4},(\mathrm{Rb}, \mathrm{Cs}) \mathrm{MoO}_{4},(\mathrm{Sr}, \mathrm{Ba}) \mathrm{ZrO}_{3},(\mathrm{Rb}, \mathrm{Cs})_{2} \mathrm{ZrO}_{3}$, and $(\mathrm{Sr}, \mathrm{Ba}) \mathrm{O}$ created as ideal solutions of the binary or ternary oxides utilizing thermochemical values within the FactSage ${ }^{\mathrm{TM}}$ set of databases $[42,43]$. These could be further aggregated to higher order phases provided information was available, and in particular to a more extensive perovskite phase.

\subsection{Additional phases and species}

Additional phases from the FactSage ${ }^{\mathrm{TM}}[42,43]$ set of databases were considered including 395 solid and 183 liquid together with 131 gaseous species. Among these were the gaseous and liquid halides, intermetallics, and binary and ternary oxides. Corcoran et al. [23] noted the importance of $\mathrm{UMoO}_{6}$ in her efforts in representing the burnup behavior of fuel, and thus the phase was included in the computational database utilizing the thermochemical values provided by Dash et al. [44].

\section{Computed chemical equilibrium state during burnup}

The thermochemical database for the phases and species was used with the FactSage ${ }^{\mathrm{TM}}$ code in global equilibrium calculations to compute the phase state in the fuel as a function of burnup. Also computed were chemical activities, including the oxygen potential. Figure 2 shows the oxygen potential as a function of temperature at a series of burnups up to $102.5 \mathrm{GWd} / \mathrm{t}$ for the compositions delineated in Fig. 1 and assuming a total pressure of $303.9 \mathrm{kPa}$ (fuel rods are pressurized with $\mathrm{He}$ at room temperature). The oxygen potential changes with burnup due to the loss of uranium to fission and changing elemental concentrations. The interplay between new element formation, dissolution of bred elements in the fluorite phase changing the nature of the phase, and the formation of secondary phases is complex and not smoothly varying with oxygen potential.

Shown in Fig. 3 is oxygen potential as a function of burnup together with the limited measured values in samples of irradiated fuel from Adamson et al. [45], Une et al. [46], Matzke [47], and Walker et al. [48]. The experimental values were obtained from the reported data, where possible, from the mid-radius position of the fuel pellet and determined at the same $750^{\circ} \mathrm{C}$ temperature. The analysis by Piro et al. [10] indicates that the experimentally inferred local burnup by Walker et al. [48], for example varies little with radial position with the exception of markedly higher values in the narrow high burnup region at the periphery of the pellet. The result is also that the experimentally inferred local burnup is only slightly lower than the average burnup value for the pellet. Absolute direct comparisons are still not possible, however, due to 
the lack of detailed knowledge of irradiation conditions and decay periods after removal from the reactor. In addition, starting $\mathrm{O} / \mathrm{U}$ ratios are but are assumed to equal 2, although in the case of Walker et al. [48] it is reported to be 2.005. Nevertheless, it may be instructive to compare computed and measured values, and one of the striking differences seen in Fig. 2 is the

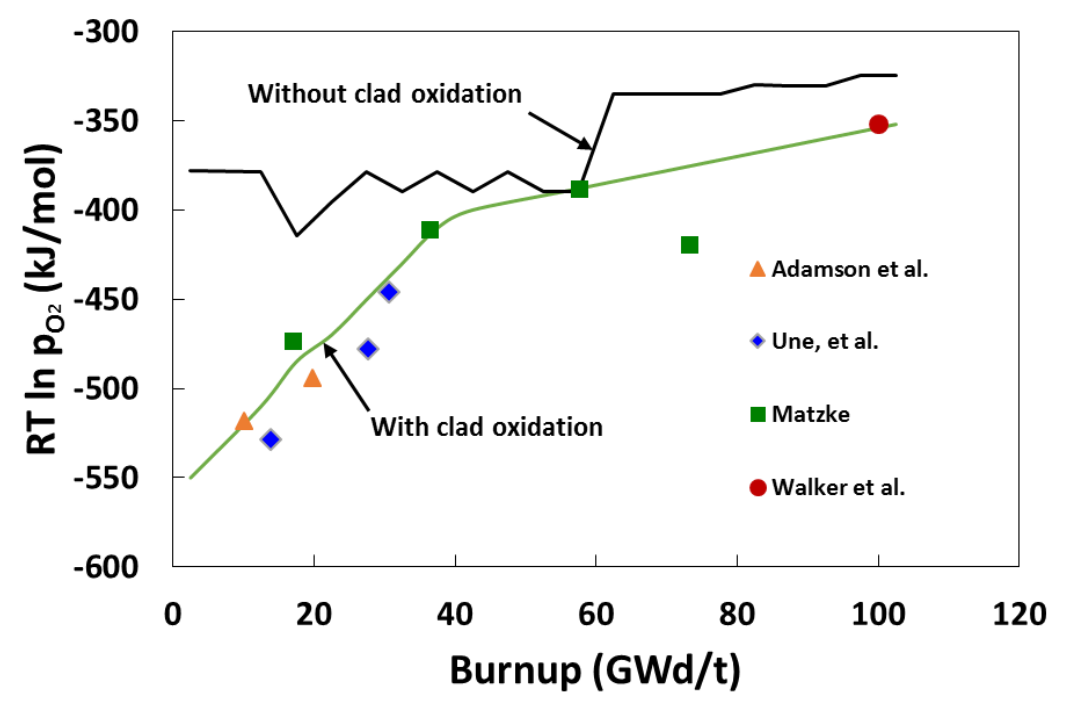

significantly more negative observed oxygen potentials at lower burnups.

Fig. 2. Computed oxygen potential at $750^{\circ} \mathrm{C}$ without and with assuming oxygen loss due to cladding oxidation.

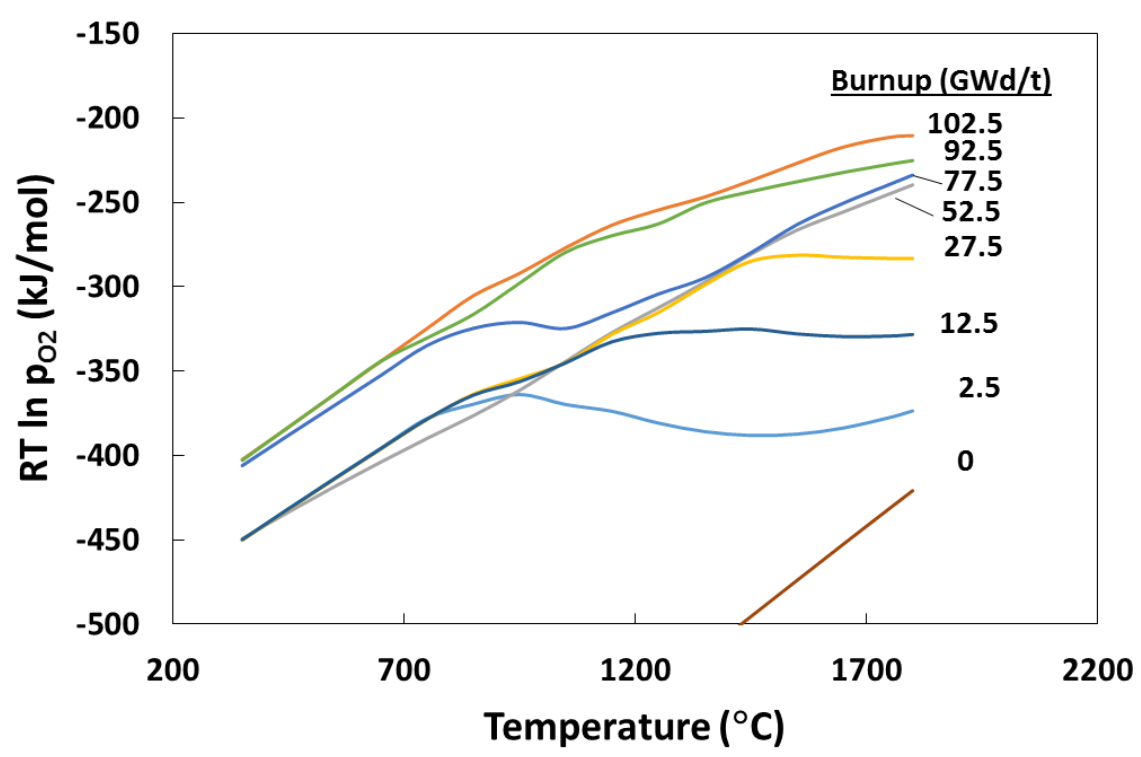

Fig. 3. Oxygen potential vs. temperature for a series of burnups to $102.5 \mathrm{GWd} / \mathrm{t}$ based on the original oxygen content, fissioned uranium and bred transuranics and fission products.

The difference between the measured and compute oxygen potentials at lower burnups may be due to loss of oxygen from fuel via oxidation of the inner surface of the cladding. To assess this possibility amounts of oxygen were removed from the calculations to better fit the measured 
oxygen potentials. The result seen in Fig. 2 shows a reasonable agreement with the experimental values given the large uncertainties. To estimate the extent of clad inner surface oxidation that would be required to suitably adjust the oxygen content in the fuel it was assumed that only the surface of the cladding adjacent to the fuel pellet will oxidize. It was also assumed that although oxygen has a significant solubility in zirconium, only the formation of $\mathrm{ZrO}_{2}$ is considered. Table 3 shows the results of the calculations that are essentially a manual fit to the measured oxygen potentials. Some variation in estimated clad oxide thickness at the higher burnups is seen in Table 3, which is likely the result of the changing computed equilibrium phase assemblage and the sensitivity of the oxygen potential to small changes in oxygen content. General agreement between the values in Table 3 and observed inner clad surface oxide layers, however, is reasonable, with Nogita and Une [49], Minne et al. [50], and Kim [51] reporting inner clad oxide layers $9-15 \mu \mathrm{m}$ in thickness for relatively high burnup fuel. Assuming the extent of clad oxidation of Table 3 , a set of oxygen potential curves as a function of temperature were computed and can be seen in Fig. 4.

\section{Table 3}

Computed cladding oxide layer thickness formed during burnup to accommodate apparent loss of oxygen from fuel pellets.

\begin{tabular}{|c|c|}
\hline $\begin{array}{c}\text { Burnup } \\
(\mathrm{GWd} / \mathrm{t})\end{array}$ & $\begin{array}{c}\text { Oxide Layer Thickness } \\
(\mu \mathrm{m})\end{array}$ \\
\hline 2.5 & 0.86 \\
\hline 12.5 & 2.27 \\
\hline 22.5 & 2.73 \\
\hline 27.5 & 5.75 \\
\hline 32.5 & 5.15 \\
\hline 37.5 & 8.34 \\
\hline 42.5 & 8.18 \\
\hline 102.5 & 7.95 \\
\hline
\end{tabular}

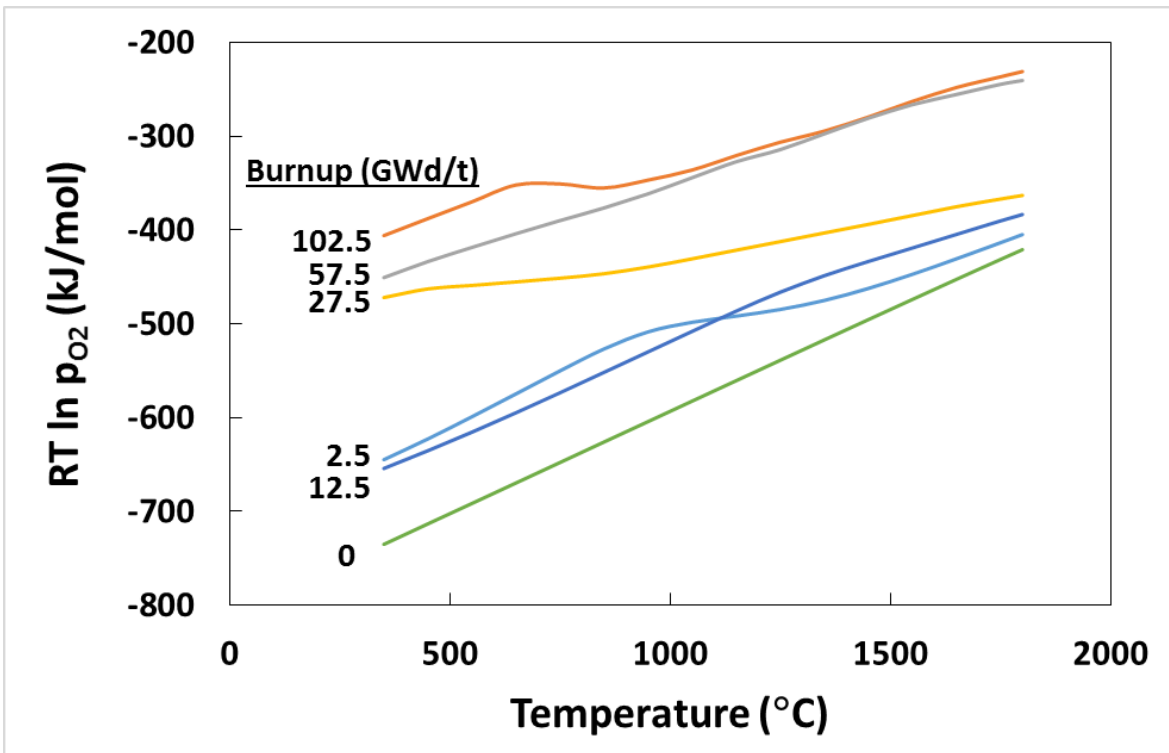


Fig. 4. Oxygen potential vs. temperature for a series of burnups to $102.5 \mathrm{GWd} / \mathrm{t}$ based on adjustments to oxygen content to account for cladding oxidation as indicated in Table 3.

As has been noted the variation in oxygen potential with burnup and temperature is due to phases which form during burnup, which to greater and lesser extent take up the oxygen released due to fission of uranium. The nature and mole fraction of phases computed to form using the database of the current effort are shown in Fig. 5, again at $750^{\circ} \mathrm{C}$. Naturally, the fluorite structure phase is the major phase and across all scenarios remains very slightly hyperstoichiometry with essentially no variation with burnup or temperature after early increase in $\mathrm{O} / \mathrm{M}$ from the starting value of 2. The hcp and fcc noble metal phases are the leading secondary phases. A number of secondary oxide phases are computed to form, including $\mathrm{BaMoO}_{4}, \mathrm{Cs}_{2} \mathrm{Zr}_{3} \mathrm{O}_{7}$, and ( $\left.\mathrm{Sr}, \mathrm{Ba}\right) \mathrm{UO}_{4}$. The Am and $\mathrm{Np}$ transuranics not included in the fluorite phase naturally appear as oxides, as does $\mathrm{Eu}$. Samarium forms a $\mathrm{Sm}_{2} \mathrm{Zr}_{2} \mathrm{O}_{7}$ phase, likely due also to its lack of inclusion in the fluorite solid solution. The significantly varying concentrations of fission product phases highlight the dynamic nature of phase formation during burnup, which is thus reflected in the oxygen potential behavior described above. Finally, the halides, and in particular iodine, appear as $\mathrm{Rb}$ or $\mathrm{Cs}$ iodide vapor species, and at lower temperatures as the RbI liquid phase as well.

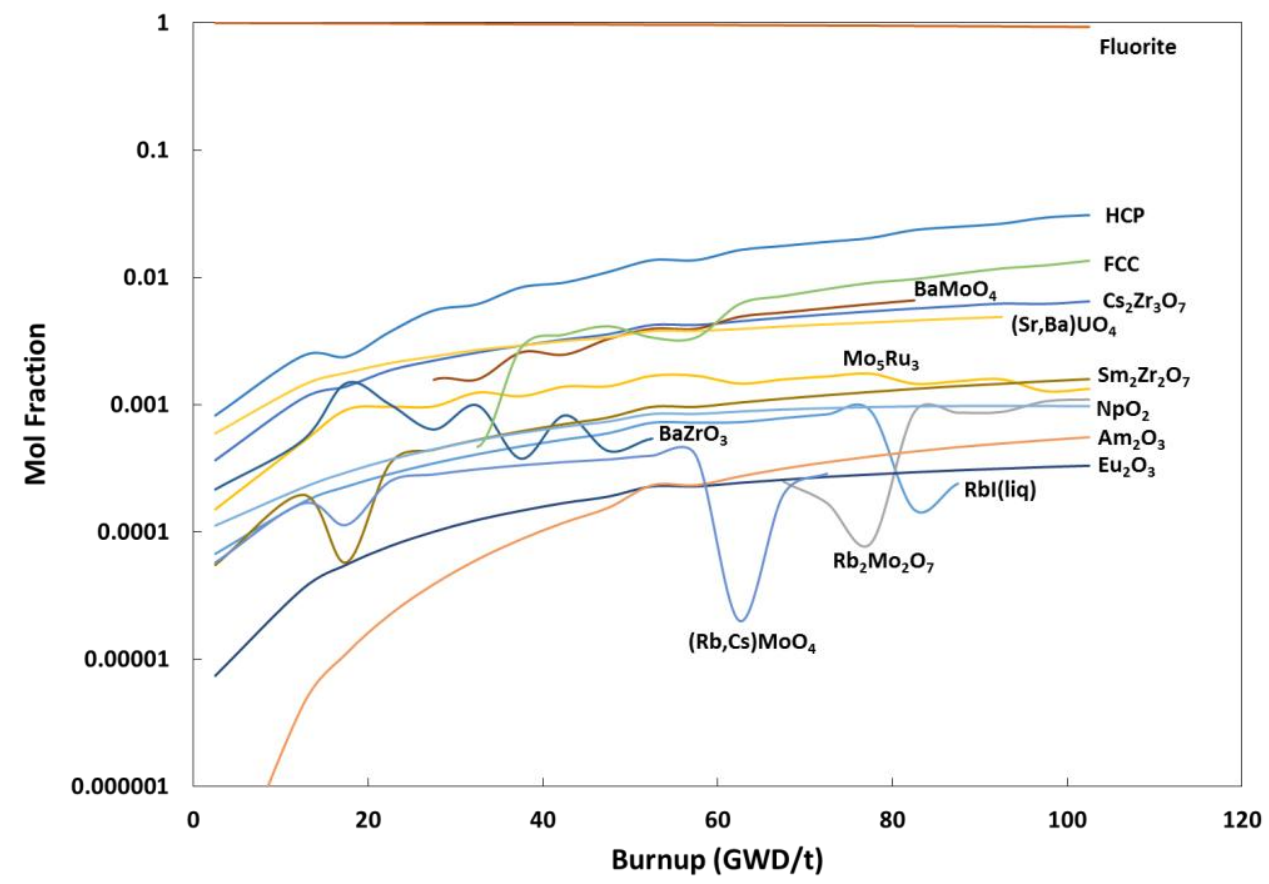

Fig. 5. Computed mole fraction of fission products vs. burnup at $750^{\circ} \mathrm{C}$ at $303.9 \mathrm{kPa}$.

One of the most important fission product elements is Mo and its behavior has been thought to buffer the oxygen potential. This seems unlikely as in fact oxygen potential appears to vary substantially with burnup/composition. The equilibrium computational results indicate the largest fraction of Mo resides in the $\mathrm{Mo}_{5} \mathrm{Ru}_{3}$ phase with lesser amounts in molybdate and noble metal alloy phases. Thus Mo is seen in both metallic and oxide phases, as would be expected. 
Secondary oxide phases have not been detected in post-irradiation examination of LWR fuel, with the exception of cesium uranate deposited at the fuel-clad interface. Such phases have, however, been observed in irradiated fast reactor oxide, including $\mathrm{Cs}_{2}(\mathrm{U}, \mathrm{Pu})_{4} \mathrm{O}_{12}$, complex perovskites, $\mathrm{Cs}_{2} \mathrm{MoO}_{4}$, and $(\mathrm{Ba}, \mathrm{Sr}) \mathrm{O}[14]$.

\section{Conclusions}

An extensive and expanding thermodynamic model for the fluorite-structure oxide fuel phase with transuranics and fission products is being developed based on assessments of ternary systems with uranium and oxygen. That model combined with library thermodynamic values for potential fission product phases as well as generated solid solution models for several other oxide solution phases and noble metal alloys makes up a database for computing the behavior of oxide fuel undergoing irradiation. This was used in a series of analyses determining the oxygen potential in prototypical PWR fuel as a function of temperature and burnup. Oxygen potential was seen to vary significantly as various phases form and disappear with increasing burnup, although the oxygen-to-metal ratio of the fluorite-structure phase remaining very slightly hyperstoichiometric. To get agreement with measured oxygen potential values, particularly at lower burnups, it was necessary to assume some loss of oxygen from the fuel, such as in oxidation of the inner surface of the cladding. Improvements in the thermochemical modeling of oxide fuel will require assessments of the remaining fission product and transuranic elements that have yet to be considered, and their inclusion in both the fluorite urania phase and potential secondary oxide phases. Ultimately, the goal would be to include accurate thermochemical prediction of fuel phase formation and chemical activities in broader fuel performance models to allow determination of thermal properties, the computation of elemental transport/partitioning, prediction of chemical reactivity related to cladding attack, and as input to models of microstructure development.

\section{Acknowledgements}

The authors wish to acknowledge the U. S. Department of Energy, Office of Nuclear Energy Nuclear Energy Advanced Modeling and Simulation Program and Fuel Cycle R\&D Program for their support of this research.

\section{References}

[1] J. Arborelius, K. Backman, L. Hallstadius, M. Limback, J. Nilsson, B. Rebensdorff, G. Zhou, K. Kitano, R. Lofstrom, G. Ronnberg, Journal of Nuclear Science and Technology 43 (2006) (9) 967.

[2] K.W. Kang, J.H. Yang, J.H. Kim, Y.W. Rhee, D.J. Kim, K.S. Kim, K.W. Song, Journal of Nuclear Science and Technology 47 (2010) (3) 304.

[3] A.R. Massih, L.O. Jernkvist, Computational Materials Science 110 (2015) 152.

[4] C. Gueneau, N. Dupin, B. Sundman, C. Martial, J.C. Dumas, S. Gosse, S. Chatain, F. De Bruycker, D. Manara, R.J.M. Konings, Journal of Nuclear Materials 419 (2011) (1-3) 145.

[5] B. Mihaila, M. Stan, J. Crapps, Journal of Nuclear Materials 430 (2012) (1-3) 221.

[6] J.C. Ramirez, M. Stan, P. Cristea, Journal of Nuclear Materials 359 (2006) (3) 174.

[7] B. Baurens, J. Sercombe, C. Riglet-Martial, L. Desgranges, L. Trotignon, P. Maugis, Journal of Nuclear Materials 452 (2014) (1-3) 578. 
[8] B.J. Lewis, W.T. Thompson, M.R. Kleczek, K. Shaheen, M. Juhas, F.C. Iglesias, Journal of Nuclear Materials 408 (2011) (3) 209.

[9] S.Y. Park, J.H. Kim, B.K. Choi, Y.H. Jeong, Metals and Materials International 13 (2007) (2) 155.

[10] M.H.A. Piro, J. Banfield, K.T. Clarno, S. Simunovic, T.M. Besmann, B.J. Lewis, W.T. Thompson, Journal of Nuclear Materials 441 (2013) (1-3) 240.

[11] M. Koizumi, M. Satoh, K. Noro, Journal of Nuclear Materials 51 (1974) (1) 90.

[12] F.T. Ewart, J.M. Horspool, G. James, R.G. Taylor, Journal of Nuclear Materials 61 (1976) (3) 254.

[13] E.H.P. Cordfunke, R.J.M. Konings, Journal of Nuclear Materials 152 (1988) (2-3) 301.

[14] H. Kleykamp, Journal of Nuclear Materials 131 (1985) (2-3) 221.

[15] H. Kleykamp, Nuclear Technology 80 (1988) (3) 412.

[16] H. Kleykamp, Journal of Nuclear Materials 206 (1993) (1) 82.

[17] T. Muromura, T. Adachi, H. Takeishi, Z. Yoshida, T. Yamamoto, K. Ueno, Journal of Nuclear Materials 151 (1988) (3) 318.

[18] J. Cobos, D. Papaioannou, J. Spino, M. Coquerelle, Journal of Alloys and Compounds 271 (1998) 610.

[19] P.G. Lucuta, R.A. Verrall, H. Matzke, B.J. Palmer, Journal of Nuclear Materials 178 (1991) (1) 48.

[20] G. Brillant, F. Gupta, A. Pasturel, Journal of Nuclear Materials 412 (2011) (1) 170.

[21] M.W.D. Cooper, S.C. Middleburgh, R.W. Grimes, Journal of Nuclear Materials 438 (2013) (1-3) 238.

[22] R.W. Grimes, C.R.A. Catlow, Philosophical Transactions of the Royal Society aMathematical Physical and Engineering Sciences 335 (1991) (1639) 609.

[23] E.C. Corcoran, B.J. Lewis, W.T. Thompson, J. Mouris, Z. He, Journal of Nuclear Materials 414 (2011) (2) 73.

[24] K. Moriyama, H. Furuya, Journal of Nuclear Science and Technology 34 (1997) (9) 900.

[25] H. Loukusa, T. Ikonen, A. Raty, V. Tulkki, Thermochemical Modelling of the Oxygen Potential of Uranium Oxide Fuel Pellets Under Irradiation, Top fuel: Reactor Fuel Performance 2015, European Nuclear Society, Zurich, Switzerland (2015).

[26] I.C. Gauld, G. Radulescu, G. Ilas, B.D. Murphy, M.L. Williams, D. Wiarda, Nuclear Technology 174 (2011) (2) 169.

[27] S.M. Bowman, Nuclear Technology 174 (2011) (2) 126.

[28] B.J. Lewis, W.T. Thompson, F.C. Iglesias, Comprehensive Nuclear Materials, Vol 2:

Material Properties/Oxide Fuels for Light Water Reactors and Fast Neutron Reactors (2012)

515.

[29] S. Imoto, Journal of Nuclear Materials 140 (1986) (1) 19.

[30] M. Hillert, Journal of Alloys and Compounds 320 (2001) (2) 161.

[31] M. Hillert, L. Kjellqvist, H. Mao, M. Selleby, B. Sundman, Calphad-Computer Coupling of Phase Diagrams and Thermochemistry 33 (2009) (1) 227.

[32] J.W. McMurray, D. Shin, B.W. Slone, T.M. Besmann, Journal of Nuclear Materials 452 (2014) (1-3) 397.

[33] J.W. McMurray, D. Shin, T.M. Besmann, Journal of Nuclear Materials 456 (2015) 142.

[34] J.W. McMurray, S. Hirooka, T. Murakami, K. Suzuki, J.T. White, S.L. Voit, A.T.

Nelson, B.W. Slone, T.M. Besmann, K.J. McClellan, M. Kato, Journal of Nuclear Materials 467 (2015) (2) 588. 
[35] R.G. Brese, J.W. McMurray, D. Shin, T.M. Besmann, Journal of Nuclear Materials 460 (2015) 5.

[36] S.M. Lee, Travis W., J.W. McMurray, T.M. Besmann, Journal of Nuclear Materials submitted (2015).

[37] Thermodynamics for Advanced Fuels-International Database.

[38] H. Matzke, H. Blank, Journal of Nuclear Materials 166 (1989) (1-2) 120.

[39] J.I. Bramman, R.M. Sharpe, D. Thom, G. Yates, Journal of Nuclear Materials 25 (1968) (2) 201.

[40] D.R. Oboyle, F.L. Brown, A.E. Dwight, Journal of Nuclear Materials 35 (1970) (3) 257.

[41] M.H. Kaye, B.J. Lewis, W.T. Thompson, Journal of Nuclear Materials 366 (2007) (1-2)

8.

[42] C. Bale, P. Chartrand, S.A. Degterov, G. Eriksson, K. Hack, R. Ben Mahfoud, J.

Melancon, A.D. Pelton, S. Petersen, Calphad-Computer Coupling of Phase Diagrams and Thermochemistry 26 (2002) (2) 189.

[43] C.W. Bale, E. Belisle, P. Chartrand, S.A. Decterov, G. Eriksson, K. Hack, I.H. Jung, Y.B. Kang, J. Melancon, A.D. Pelton, C. Robelin, S. Petersen, Calphad-Computer Coupling of Phase Diagrams and Thermochemistry 33 (2009) (2) 295.

[44] S. Dash, K. Jayanthi, Z. Singh, N.D. Dahale, S.C. Parida, V.S. Iyer, Journal of Alloys and Compounds 296 (2000) (1-2) 166.

[45] M.G. Adamson, E.A. Aitken, S.K. Evans, J.H. Davies, Oxygen redistribution and its measurement in irradiated oxide fuels, Thermodynamics of Nuclear Materials 1974, IAEA, Vienna, Austria (1974), p.59-71.

[46] K. Une, Y. Tominaga, S. Kashibe, Journal of Nuclear Science and Technology 28 (1991) (5) 409.

[47] H. Matzke, Journal of Nuclear Materials 208 (1994) (1-2) 18.

[48] C.T. Walker, V.V. Rondinella, D. Papaioannou, S. Van Winckel, W. Goll, R. Manzel, Journal of Nuclear Materials 345 (2005) (2-3) 192.

[49] K. Nogita, K. Une, Journal of Nuclear Science and Technology 34 (1997) (7) 679.

[50] J.B. Minne, L. Desgranges, V. Optasanu, N. Largenton, L. Raceanu, T. Montesin, Diffusion in Materials - Dimat 2011 323-325 (2012) 227.

[51] K.T. Kim, Journal of Nuclear Materials 404 (2010) (2) 128. 